\title{
Safety and Efficacy of Intravenous Golimumab in Adults with Ankylosing Spondylitis: Results through 1 Year of the GO-ALIVE Study
}

\author{
John D. Reveille, Atul Deodhar, Paul H. Caldron, Anna Dudek, Diane D. Harrison, \\ Lilianne Kim, Kim Hung Lo, Jocelyn H. Leu, and Elizabeth C. Hsia
}

ABSTRACT. Objective. Evaluate safety and efficacy of intravenous (IV) golimumab (GOL) in patients with active ankylosing spondylitis (AS) through 1 year.

Methods. A total of 208 patients were randomized to IV infusions of GOL $2 \mathrm{mg} / \mathrm{kg}(\mathrm{n}=105)$ at weeks 0,4 , and every 8 weeks thereafter or placebo $(n=103)$ at weeks 0,4 , and 12 , then crossover to GOL at weeks 16, 20, and every 8 weeks thereafter through Week 52. Efficacy was assessed using the Assessment of Spondyloarthritis international Society (ASAS) criteria, the Ankylosing Spondylitis Disease Activity Score (ASDAS), the Bath Ankylosing Spondylitis Disease Activity Index (BASDAI), and the Bath Ankylosing Spondylitis Functional Index (BASFI). Health-related quality of life was assessed using the AS Quality of Life (ASQoL) index. Efficacy and safety were monitored through Week 52 and Week 60, respectively.

Results. The primary endpoint (ASAS20) and all controlled endpoints at Week 16 were achieved. At Week 52, 69.5\% and $65.0 \%$ of patients in the GOL group and placebo crossover group, respectively, achieved an ASAS20; 56.2\% and 51.5\% achieved an ASAS40; 56.2\% and 55.3\% achieved a BASDAI50; $24.8 \%$ and $24.3 \%$ achieved ASAS partial remission; and $25.7 \%$ and $26.2 \%$ met ASDAS inactive disease criteria (all last observation carried forward). Mean changes from baseline to Week 52 in BASFI and ASQoL scores were similar between the GOL group and the placebo crossover group (BASFI: -2.7 and -2.6; ASQoL: -5.5 and -5.4 ). Through Week 60, 55.4\% of all GOL-treated patients had $\geq 1$ adverse events (AE); $3.4 \%$ had $\geq 1$ serious AE.

Conclusion. Efficacy was maintained through 1 year with IV GOL $2 \mathrm{mg} / \mathrm{kg}$ among patients with active AS. AE were consistent with the known safety profile of GOL. (First Release April 152019 ; J Rheumatol 2019;46:1277-83; doi:10.3899/jrheum.180718)

Key Indexing Terms:

ANKYLOSING SPONDYLITIS GOLIMUMAB

BIOLOGICS

ANTI-TUMOR NECROSIS FACTOR THERAPY

\section{INTRAVENOUS}

From the University of Texas McGovern Medical School, Houston, Texas; Oregon Health \& Science University, Portland, Oregon; Arizona Arthritis and Rheumatology Associates, Phoenix, Arizona; Janssen Research \& Development LLC, Spring House, Pennsylvania; University of

Pennsylvania, Philadelphia, Pennsylvania, USA; AMED Medical Center, Warsaw, Poland.

This study was funded by Janssen Research \& Development LLC, which manufactures golimumab.

Drs. Caldron and Dudek served as trial investigators for Janssen. Dr. Reveille has received consultancies from Eli Lilly, Janssen, Novartis, Pfizer, and UCB, has served as a trial investigator for Janssen and Eli Lilly, and has received a research grant from Janssen. Dr. Deodhar has received consultancies, speaking fees, and/or honoraria from Eli Lilly, Janssen, Novartis, Pfizer, and UCB. Drs. Harrison and Hsia, and L. Kim, K.H. Lo, and J.H. Leu are or were employees of Janssen Research \& Development LLC at the time this work was performed, and own stock in Johnson \& Johnson, of which Janssen Research \& Development LLC is a wholly owned subsidiary.

J.D. Reveille, MD, University of Texas McGovern Medical School; A. Deodhar, MD, Oregon Health \& Science University; P.H. Caldron, DO, Arizona Arthritis and Rheumatology Associates; A. Dudek, MD, PhD, AMED Medical Center; D.D. Harrison, MD, MPH, Janssen Research \& Development LLC; L. Kim, PhD, Janssen Research \& Development LLC; K.H. Lo, PhD, Janssen Research \& Development LLC; J.H. Leu, PharmD, PhD, Janssen Research \& Development LLC; E.C. Hsia, MD, MSCE,

\author{
Janssen Research \& Development LLC, and University of Pennsylvania. \\ Address correspondence to Dr. E.C. Hsia, Janssen Research \& \\ Development LLC, 1400 McKean Road, PO Box 776, Spring House, \\ Pennsylvania 19477,USA.E-mail: ehsia@its.jnj.com \\ Full Release Article. For details see Reprints and Permissions at \\ jrheum.org \\ Accepted for publication November 22, 2018.
}

Ankylosing spondylitis (AS) is an immune-mediated disease characterized by inflammatory back pain and progressive spinal stiffness ${ }^{1}$. As the disease progresses, there is a decrease in spinal mobility and physical function, and an increase in disability. This can lead to substantial impairment in health-related quality of life (HRQOL) ${ }^{2}$. Current treatment recommendations for AS include the use of nonsteroidal antiinflammatory drugs (NSAID), with initiation of anti-tumor necrosis factor (TNF) agents for patients with active disease despite treatment with NSAID ${ }^{3}$.

Shared decision making with patients can improve treatment satisfaction ${ }^{4}$ and is part of the treatment discussion between patients and healthcare providers. Therapies are

Personal non-commercial use only. The Journal of Rheumatology Copyright (c) 2019. All rights reserved. 
available with a variety of dosing frequencies and routes of administration, and patients may have preferences related to these factors. In a study of patients with rheumatoid arthritis who were receiving anti-TNF therapy, patients who preferred subcutaneous (SC) therapy indicated a preference for self-administration at home, while patients who preferred intravenous (IV) therapy expressed a preference for receiving therapy in the presence of a hospital or physician ${ }^{5}$. Frequency of administration was cited as a preference for patients receiving IV therapy, but not SC therapy ${ }^{5}$.

The GO-ALIVE trial evaluated the safety and efficacy of IV golimumab (GOL), a monoclonal anti-TNF antibody, in patients with $\mathrm{AS}^{6}$. Through the placebo-controlled period of the GO-ALIVE trial (Week 16), patients who received IV GOL $2 \mathrm{mg} / \mathrm{kg}$ had greater improvements in the signs and symptoms of AS than did patients receiving placebo, and these improvements were maintained through Week $28^{6}$. In addition, adverse events (AE) that occurred through Week 28 were consistent with the known safety profile of IV GOL and other anti-TNF agents ${ }^{6}$. Clinical efficacy, safety, and pharmacokinetic results through 1 year of the GO-ALIVE trial are reported herein.

\section{MATERIALS AND METHODS}

Patients and study design. Detailed eligibility criteria and study design were previously reported ${ }^{6}$. Adults with a diagnosis of AS ("definite" using the modified New York criteria) for $\geq 3$ months with signs of active disease and inadequate response or intolerance to NSAID were eligible for inclusion in GO-ALIVE. Up to $10 \%$ of the study population could have complete ankylosis of the spine. Eligible patients were randomly assigned to receive IV infusions of placebo at weeks 0,4 , and 12 or GOL $2 \mathrm{mg} / \mathrm{kg}$ at weeks 0 , 4 , and every 8 weeks thereafter through Week 52 . Patients in the placebo group crossed over to receive GOL $2 \mathrm{mg} / \mathrm{kg}$ at weeks 16,20 , and every 8 weeks thereafter through Week 52.

Stable doses of methotrexate (MTX; $\leq 25 \mathrm{mg} /$ week), sulfasalazine (SSZ), hydroxychloroquine (HCQ), NSAID, other analgesics, and low-dose oral corticosteroids (dose equivalent to $\leq 10 \mathrm{mg}$ prednisone/day) were permitted for patients who were receiving these medications at baseline. Patients could not have received systemic disease-modifying antirheumatic drugs other than MTX, SSZ, or HCQ within 4 weeks of the first study agent administration. Up to $20 \%$ of the study population could have received a prior anti-TNF therapy other than GOL; these patients could not have discontinued the prior anti-TNF agent because of primary treatment failure and could not have received anti-TNF therapy within 3 months of the first study agent administration (except for etanercept within 6 weeks).

Assessments. As previously reported, the primary endpoint was the proportion of patients with an improvement of $\geq 20 \%$ in the Assessment of Spondyloarthritis international Society criteria (ASAS20 response) at Week $16^{6}$. The proportions of patients achieving an ASAS20 response, ASAS40 response, ASAS partial remission (score < 2), and ASAS 5/6 response ${ }^{7}$ were evaluated through Week 52. In addition, disease activity was also assessed using the Ankylosing Spondylitis Disease Activity Score (ASDAS; inactive disease, score $<1.3$; major improvement, decrease $\geq 2.0$; and clinically important improvement, decrease $\geq 1.1)^{8,9}$ and the Bath Ankylosing Spondylitis Disease Activity Index (BASDAI ${ }^{10}$. Maintenance of response at Week 52 was determined among those patients who had an ASAS20 response, ASAS40 response, ASDAS inactive disease, or BASDAI50 response at Week 16. Physical function was assessed using the Bath Ankylosing Spondylitis Functional Index (BASFI) ${ }^{11}$. Enthesitis was assessed using the University of California San Francisco enthesitis index ${ }^{12}$.
HRQOL was evaluated using the 36-item Medical Outcomes Study Short Form-36 (SF-36) physical component summary (PCS) and mental component summary (MCS) scores ${ }^{13}$ and the AS Quality of Life (ASQoL) score $^{14}$. Improvements in spinal mobility were assessed using the Bath Ankylosing Spondylitis Metrology Index (BASMI) ${ }^{15}$.

AE were monitored through Week 60. Serum samples were collected to measure GOL concentrations and evaluate for the presence of antibodies to GOL using a highly sensitive, drug-tolerant, enzyme immunoassay (EIA).

Statistical methods. Clinical efficacy results through Week 52 were summarized by randomized treatment group (intent-to-treat) using descriptive statistics (counts and percentages for discrete variables; means and SD for continuous variables). No formal comparisons were performed for timepoints after Week 16, when patients in the placebo group crossed over to GOL. Missing data were imputed using last observation carried forward methods. For dichotomous composite endpoints with all components missing, nonresponder imputation was used through Week 52. No treatment failure rules ${ }^{6}$ were applied after Week 16 .

AE through Week 60 were summarized by the treatment actually received and included all patients who received at least 1 administration of GOL (all GOL group). Pharmacokinetic and immunogenicity analyses included all patients who had received $\geq 1 \mathrm{GOL}$ administration and had $\geq 1$ post-GOL administration serum sample to assess serum GOL concentration.

\section{RESULTS}

Patients. Baseline characteristics and patient disposition through Week 28 have been previously reported ${ }^{6}$. Briefly, 208 patients were randomized to receive placebo $(n=103)$ or GOL $2 \mathrm{mg} / \mathrm{kg}(\mathrm{n}=105)$. Baseline demographic and disease characteristics were well balanced between the treatment groups ${ }^{6}$. Through Week 60 , nine patients in the placebo group (4 prior to crossover to GOL at Week 16 and 5 after Week 16) and 8 patients in the GOL group discontinued study treatment (Figure 1). Overall, the most common reasons for discontinuing the study agent throughout the study were withdrawal of consent $(n=9)$ and $\operatorname{AE}(n=4)$.

Clinical efficacy. The primary endpoint was achieved, with $73.3 \%$ of patients in the GOL group achieving an ASAS20 response at Week 16 compared with $26.2 \%$ in the placebo group $^{6}$. As previously reported ${ }^{6}$, greater proportions of patients in the GOL group achieved an ASAS40 response, ASAS partial remission, ASAS 5/6 response, BASDAI50 response, BASDAI70 response, and ASDAS inactive disease compared with the placebo group at Week 16 . The proportion of patients who had a clinically important improvement in ASDAS from baseline was greater in the GOL group at Week $16(82.7 \%$ vs $22.5 \%$; $\mathrm{p}<0.001)$; response rates for patients with a clinically important improvement in ASDAS were similar in the 2 treatment groups at weeks 28 (GOL: 76.9\%; placebo crossover: $71.6 \%$ ) and 52 (GOL: $76.0 \%$; placebo crossover: $71.6 \%$; Table 1). Following placebo crossover to GOL at Week 16, the proportions of patients achieving an ASAS20, ASAS40, ASDAS inactive disease, or BASDAI50 response in the placebo group approached those observed in the GOL group, as early as Week 20 (4 weeks after crossover to GOL) ${ }^{6}$ and remained steady through Week 52 (Figure 2) in both treatment groups. Additionally, among those patients who achieved an ASAS20, ASAS40, ASDAS inactive 


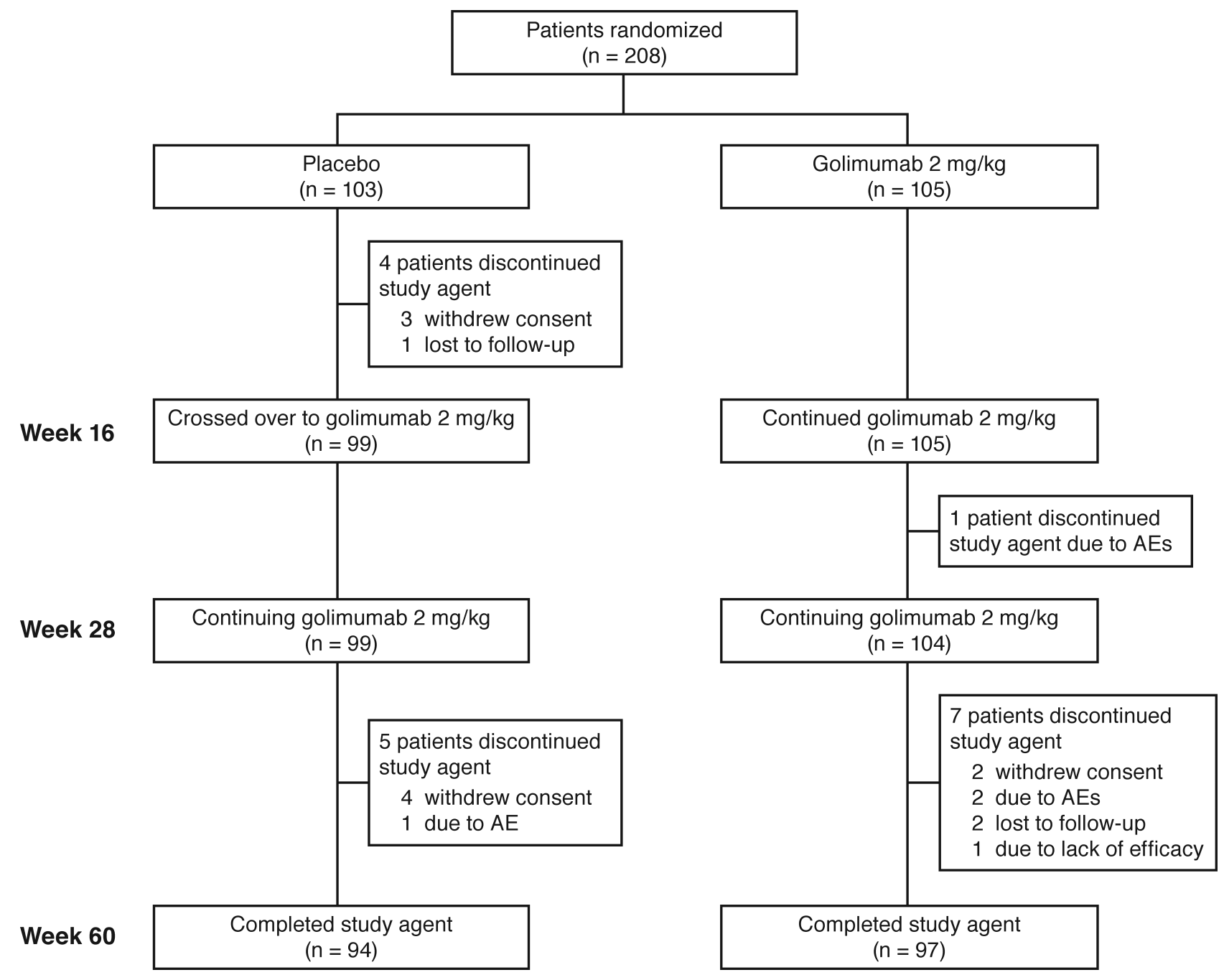

Figure 1. Patient disposition through Week 60. AE: adverse event.

disease, or BASDAI50 response at Week 16, most maintained this response at Week 52 (Table 2). In addition, mean changes from baseline in BASFI and BASMI scores were similar between the treatment groups at Week 52, when all patients had been receiving GOL after the placebo crossover at Week 16 (Table 1).

Among patients with enthesitis at baseline, the mean change from baseline in enthesitis score was also maintained from Week 28 through Week 52 in both treatment groups (GOL: -3.8; placebo crossover: -3.6; Table 1). A greater proportion of patients in the GOL group had an enthesitis score of 0 (resolution of enthesitis) at Week 16 compared with placebo $(43.7 \%$. vs $14.1 \%$; p < 0.0001). After placebo crossover to GOL, $47.1 \%$ in the GOL group and $42.4 \%$ of patients in the placebo crossover group had resolution of enthesitis at Week 28, and $59.8 \%$ and $42.4 \%$, respectively, had resolution of enthesitis at Week 52.

Improvements in SF-36 PCS/MCS and ASQoL scores were greater for patients in the GOL group compared with placebo at Week $16^{6}$. These improvements were maintained at Week 52 and were similar between the 2 treatment groups (Table 1).

$A E$. Through Week 60, 204 patients received at least 1 administration of GOL, including 99 patients who crossed over from placebo at Week 16 and 105 patients who were randomized to GOL at baseline. AE that occurred through Week 16 (placebo-controlled period) and through Week 28 have been previously described in detail ${ }^{6}$. Cumulative safety results through Week 60 are presented in Table 3. Among all GOL-treated patients, 55.4\% had $\geq 1$ AE through Week 60 . The most common type of AE was infection $(n=67,32.8 \%)$. The most common AE were nasopharyngitis (11.8\%), upper respiratory tract infection $(7.4 \%)$, and alanine aminotransferase (ALT) increase $(5.9 \%)$. Three $(1.5 \%)$ GOL-treated patients had a serious infection; one (pneumonia) occurred in a patient in the GOL group before Week 16 and was previ-

Personal non-commercial use only. The Journal of Rheumatology Copyright $\subset$ 2019. All rights reserved. 
Table 1. Efficacy at Week $52^{\mathrm{a}}$.

\begin{tabular}{lcc}
\hline Variables & Placebo $\rightarrow$ GOL, $2 \mathrm{mg} / \mathrm{kg}$ & $\mathrm{GOL}, 2 \mathrm{mg} / \mathrm{kg}$ \\
\hline Patients randomized, $\mathrm{n}$ & 103 & 105 \\
Clinical efficacy & & \\
ASAS20 & $67(65.0)$ & $73(69.5)$ \\
ASAS40 & $53(51.5)$ & $59(56.2)$ \\
ASAS partial remission & $25(24.3)$ & $26(24.8)$ \\
ASAS 5/6 response & $56(54.4)$ & $69(65.7)$ \\
BASDAI50 & $57(55.3)$ & $59(56.2)$ \\
BASDAI70 & $36(35.0)$ & $35(33.3)$ \\
ASDAS inactive disease & $27(26.2)$ & $27(25.7)$ \\
ASDAS major improvement & $46(45.1)$ & $48(46.6)$ \\
ASDAS clinically important improvement from baseline & $73(71.6)$ & $-0.4 \pm 0.6$ \\
BASMI, change from baseline & $-0.4 \pm 0.7$ & $-2.7 \pm 2.5$ \\
BASFI, change from baseline & $-2.6 \pm 2.5$ & 87 \\
Enthesitis & & $-3.8 \pm 5.0$ \\
n & & \\
Change from baseline & 85 & 104 \\
HRQOL & $-3.6 \pm 4.0$ & $-5.5 \pm 5.3$ \\
Patients, n & & $9.5 \pm 8.8$ \\
Change from baseline & 102 & $7.3 \pm 10.6$ \\
ASQoL & & \\
SF-36 PCS & $-5.4 \pm 5.3$ & $9.7 \pm 8.1$ \\
SF-36 MCS & $5.1 \pm 11.9$ & \\
\hline
\end{tabular}

Data are presented as mean \pm SD or $\mathrm{n}(\%)$ unless otherwise specified. ${ }^{a}$ Missing data were imputed using last observation carried forward. For dichotomous composite endpoints with all components missing, nonresponder imputation was used through Week 52. ${ }^{\mathrm{b}}$ Among patients with enthesitis at baseline. GOL: golimumab; ASAS20/40: $\geq 20 \% / 40 \%$ improvement in Assessment of SpondyloArthritis international Society criteria; ASDAS: Ankylosing Spondylitis Disease Activity Score; ASQoL: Ankylosing Spondylitis Quality of Life; BASDAI50/70: 50\%/70\% improvement in Bath Ankylosing Spondylitis Disease Activity Index; BASFI: Bath Ankylosing Spondylitis Functional Index; BASMI: Bath Ankylosing Spondylitis Metrology Index; HRQOL: health-related quality of life; SF-36: 36-item Medical Outcomes Study Short Form; PCS: physical summary score; MCS: mental summary score.

ously reported ${ }^{6}$. The other 2 serious infections occurred after Week 28: one patient had appendicitis, and one patient had pulmonary tuberculosis (Ukraine; screened negative for tuberculosis by QuantiFERON-TB Gold test and chest radiograph). Four patients discontinued the study agent owing to an AE; all had been treated with GOL. One patient [increased ALT and increased aspartate aminotransferase (AST)] was previously reported ${ }^{6}$, and 3 discontinued after Week 28 (increased ALT, pulmonary tuberculosis, and rash).

A total of 8 serious AE (SAE) occurred; 2 occurred through Week 16 (pancreatitis and pneumonia, both in the GOL group) ${ }^{6}$. After Week 16, six SAE occurred: appendicitis, pulmonary tuberculosis, sinus tachycardia, nonalcoholic steatohepatitis, wrist fracture, and Henoch-Schönlein purpura (same patient who had pneumonia). There were no opportunistic infections, demyelinating events, malignancies, or deaths during the study. In addition, there was a nonserious report of acute hepatitis B at Week 60 in a patient who screened negative for hepatitis B at baseline.

Cumulatively through Week 60, sixty-five of the 204 GOL-treated patients who had an ALT level in the normal range at baseline had a maximum postbaseline value above the upper limit of normal (ULN). Of these patients, 63 had an ALT level $<3 \times$ ULN, and 1 patient had an ALT level $\geq 3$ to $<5 \times$ ULN. One patient had an ALT level $\geq 8 \times$ ULN (the patient diagnosed with acute hepatitis B infection at Week $60)$.

Additionally, 35 of the 204 GOL-treated patients had an AST level at baseline that was within the normal range and a maximum postbaseline level that was above the ULN. All increases were $<2 \times U L N$, except for the patient with acute hepatitis B who had a postbaseline AST level $\geq 5$ to $<8$ $\times$ ULN

Among the subset of 21 GOL-treated patients who received tuberculosis prophylaxis, 10 had an elevated postbaseline ALT level. Nine of these patients had an ALT level $<3 \times$ ULN; 1 patient had an ALT level $\geq 8 \times$ ULN (patient with acute hepatitis B).

A total of $1500 \mathrm{GOL}$ infusions were administered. Four infusion reactions, defined as an AE that occurred during the infusion or within $1 \mathrm{~h}$ following the end of study agent administration, were reported in 3 patients, all during the placebo-controlled period ${ }^{6}$. None was considered serious or severe, and none led to discontinuation of study agent. No additional infusion reactions occurred through Week 60.

Pharmacokinetics and immunogenicity. Median trough

Personal non-commercial use only. The Journal of Rheumatology Copyright @ 2019 . All rights reserved. 
A

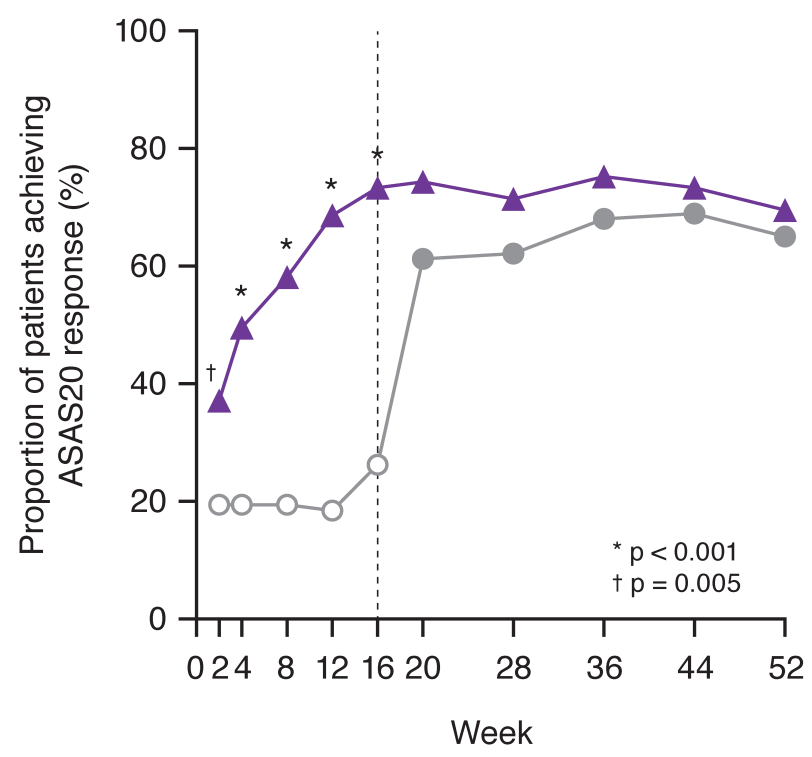

C

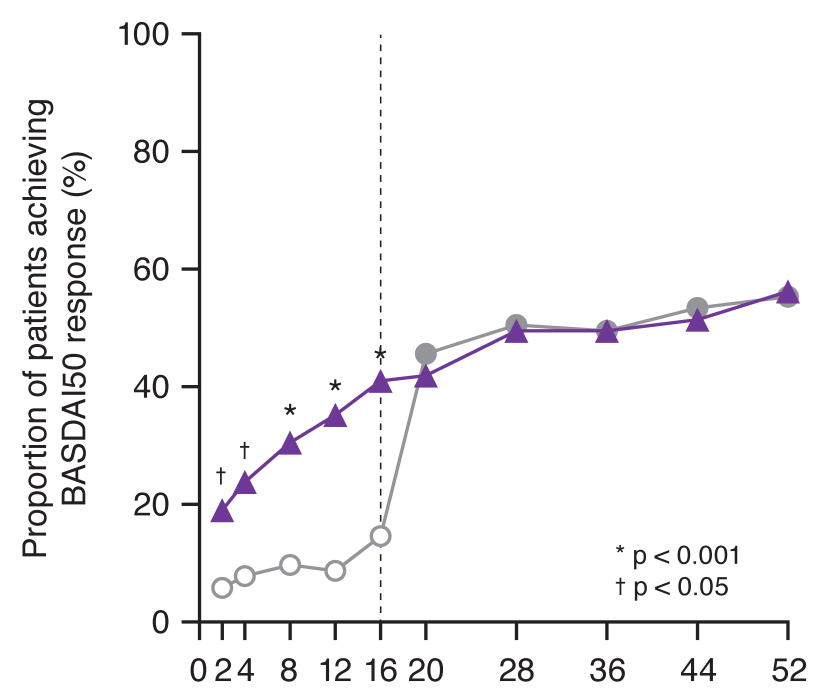

B

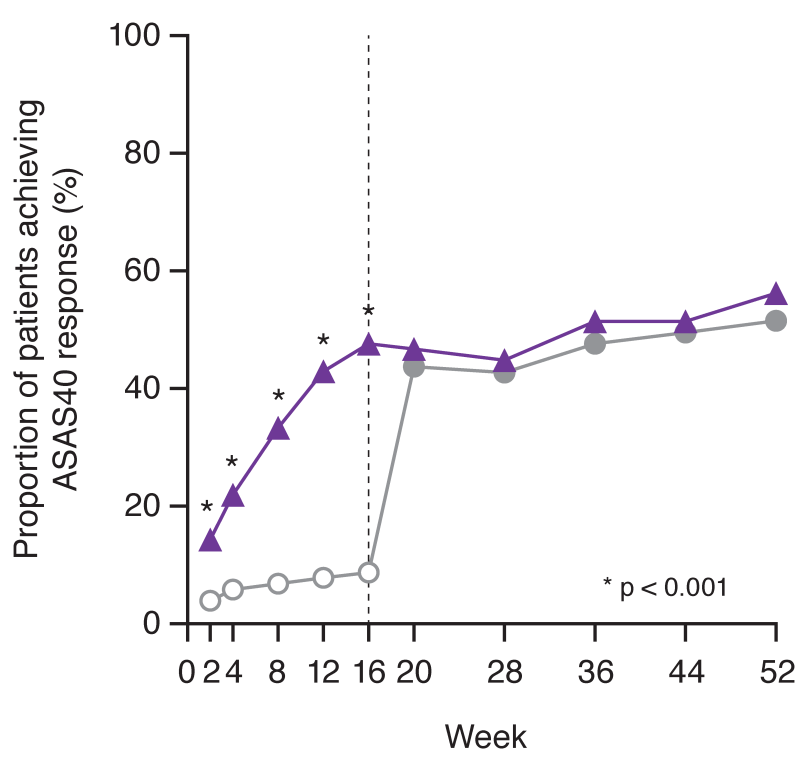

D

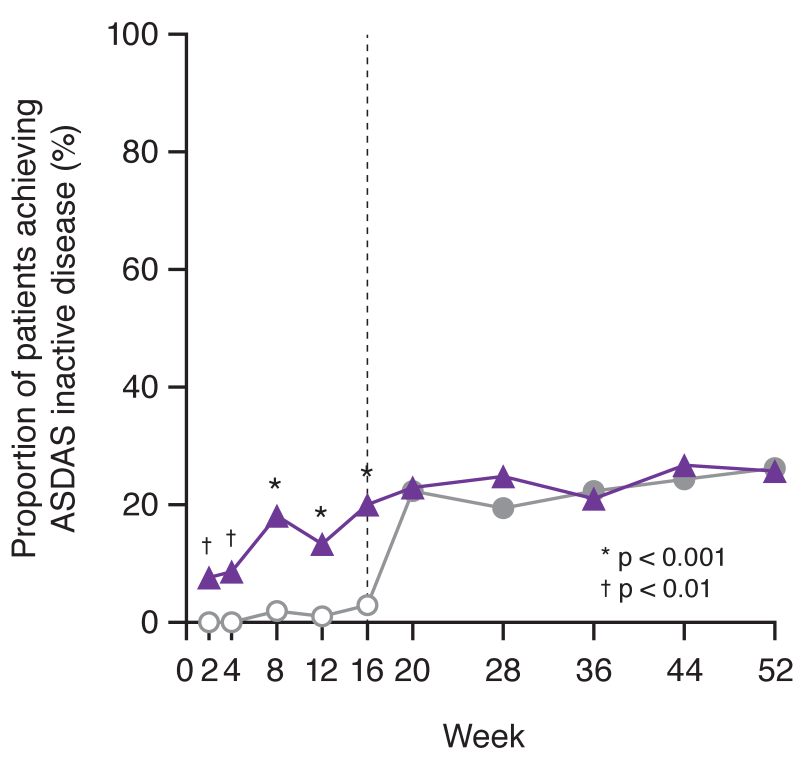

Week

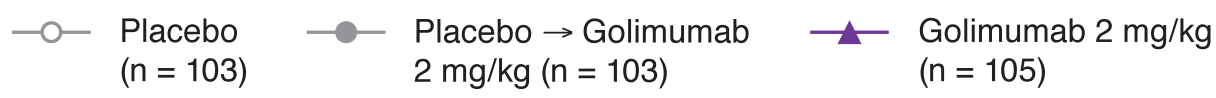

Figure 2. Proportions of patients achieving an (A) ASAS20 response, (B) ASAS40 response, (C) BASDAI50 response, and (D) ASDAS inactive disease through Week 52. Patients randomized to placebo crossed over to golimumab $2 \mathrm{mg} / \mathrm{kg}$ at Week 16 (dotted line). Missing data were imputed using last observation carried forward. For dichotomous composite endpoints with all components missing, nonresponder imputation was used through Week 52. ASAS20/40: $\geq 20 \% / 40 \%$ improvement in Assessment of SpondyloArthritis international Society criteria; ASDAS: Ankylosing Spondylitis Disease Activity Score; BASDAI50: $50 \%$ improvement in Bath Ankylosing Spondylitis Disease Activity Index.

serum GOL concentrations reached steady state by Week 12 in the GOL group ${ }^{6}$ and were maintained through Week 52; patients in the placebo group who crossed over to GOL at Week 16 had similar median serum GOL concentrations from Week 20 through Week 52. Through Week 52, 203 patients received $\geq 1$ GOL infusion and had $\geq 1$ postbaseline serum sample available for evaluating immunogenicity using the drug-tolerant EIA method. Of these, $41(20.2 \%)$ tested positive for antibodies to GOL, 12 of whom tested positive for neutralizing antibodies. Given the higher sensitivity of the drug-tolerant EIA method, most patients who tested positive had a low titer $(<1: 1000)$. Patients with titers $<1: 1000$ typically had detectable trough GOL concentrations, while the 2 patients with titers $\geq 1: 1000$ had trough

$$
\text { Personal non-commercial use only. The Journal of Rheumatology Copyright @ } 2019 \text {. All rights reserved. }
$$


Table 2. Maintenance of efficacy from Week 16 to Week $52^{\mathrm{a}}$.

\begin{tabular}{lc}
\hline Variables & GOL 2 mg/kg \\
\hline Patients randomized, $\mathrm{n}$ & 105 \\
Week 16 responders with response at Week 52, n/N (\%) & \\
ASAS20 & $63 / 77(81.8)$ \\
ASAS40 & $45 / 50(90.0)$ \\
BASDAI50 & $38 / 43(88.4)$ \\
ASDAS inactive disease & $15 / 21(71.4)$ \\
\hline
\end{tabular}

${ }^{a}$ Missing data were imputed using last observation carried forward. For dichotomous composite endpoints with all components missing, nonresponder imputation was used through Week 52. GOL: golimumab; ASAS20/40: $\geq 20 \% / 40 \%$ improvement in Assessment of SpondyloArthritis international Society criteria; ASDAS: Ankylosing Spondylitis Disease Activity Score; BASDAI50: 50\% improvement in Bath Ankylosing Spondylitis Disease Activity Index.

concentrations below the lower limit of quantification at weeks 20,36, and 52. No infusion reactions occurred in patients who tested positive for antibodies to GOL. Among GOL-treated patients who tested negative for antibodies to GOL $(\mathrm{n}=157), 73.2 \%$ achieved an ASAS20 response and $59.2 \%$ achieved an ASAS40 response at Week 52; among those who tested positive for antibodies to GOL $(\mathrm{n}=39)$, $64.1 \%$ achieved an ASAS20 response, and $48.7 \%$ achieved an ASAS40 response. There was no apparent relationship by antibody titers; however, the relatively small number of patients in each titer group limits interpretation (data not shown).

\section{DISCUSSION}

In the phase III GO-ALIVE trial of patients with active AS, the primary endpoint was achieved at Week 16 with 73.3\% of patients randomized to receive GOL achieving an ASAS20 response compared with $26.2 \%$ of patients randomized to placebo $^{6}$. Following placebo crossover to GOL at Week 16 , patients in the placebo crossover group achieved efficacy responses similar to those observed in the patients who had received GOL from baseline, as assessed by ASAS criteria and BASDAI and ASDAS scores. Among patients in the placebo crossover group, response to GOL at Week 20, four weeks after patients in this group initiated GOL therapy, was generally similar to that observed among patients who had been receiving GOL from baseline. This rapid improvement may be at least partially attributed to the placebo response occurring through Week 16 in these patient-driven outcomes, with further improvement upon switching to GOL. A consistent, high level of response was observed in both treatment groups through 1 year. GOL concentrations were also maintained at steady state in both treatment groups through 1 year. The proportions of patients who achieved ASAS20 and ASAS40 responses at Week 52 were slightly lower for patients who were positive for antibodies to GOL compared with those who tested negative; however, a positive antibody-to-GOL status did not preclude clinical response. The drug-tolerant EIA method is highly sensitive; most of the patients who tested positive for antibodies to GOL had low titers and detectable trough GOL concentrations. Two patients had titers $\geq 1: 1000$, and these patients had undetectable trough GOL concentrations beyond Week 20.

Improvements in HRQOL were also maintained through 1 year with IV GOL. At Week 52,69.5\% of all GOL-treated patients achieved an ASAS20 response and 56.2\% achieved an ASAS40 response. Of note, most patients who had an ASAS20, ASAS40, ASDAS inactive disease, or BASDAI50 response at Week 16 were also in response at Week 52.

Few patients discontinued study treatment through 1 year, with over $90 \%$ of patients completing study infusions through Week 52. Discontinuation rates were similar

Table 3. Adverse events (AE) through Week 60.

\begin{tabular}{lcccc}
\hline Variables & Placebo & $\begin{array}{c}\text { Placebo } \rightarrow \text { GOL } \\
2 \mathrm{mg} / \mathrm{kg}\end{array}$ & $\begin{array}{c}\text { GOL, } \\
2 \mathrm{mg} / \mathrm{kg}\end{array}$ & $\begin{array}{c}\text { All GOL, } \\
2 \mathrm{mg} / \mathrm{kg} *\end{array}$ \\
\hline Patients, $\mathrm{n}$ & & 99 & 105 & 204 \\
Mean duration of followup, weeks & 103 & 43.7 & 59.4 & 51.8 \\
Patients who discontinued owing to AE & 16.1 & $1(1.0)$ & $3(2.9)$ & $4(2.0)$ \\
Patients with $\geq 1$ AE & $24(23.3)$ & $48(48.5)$ & $65(61.9)$ & $113(55.4)$ \\
Patients with $\geq 1$ infection & $8(7.8)$ & $25(25.3)$ & $42(40.0)$ & $67(32.8)$ \\
Patients with $\geq 1$ infusion reaction & 0 & 0 & $3(2.9)$ & $3(1.5)$ \\
Patients with $\geq 1$ SAE & 0 & $1(1.0)$ & $6(5.7)$ & $7(3.4)$ \\
Serious infections & 0 & 0 & $3(2.9)$ & $3(1.5)$ \\
Tuberculosis & 0 & 0 & $1(1.0)$ & $1(0.5)$ \\
Opportunistic infections & 0 & 0 & 0 & 0 \\
Demyelinating events & 0 & 0 & 0 & 0 \\
Malignancies & 0 & 0 & 0 & 0 \\
Deaths & 0 & 0 & 0 & 0 \\
\hline
\end{tabular}

Data are presented as $\mathrm{n}(\%)$ unless otherwise specified. * Includes all patients randomized to the placebo group who crossed over to GOL at Week 16 and patients randomized to the GOL group at baseline. GOL: golimumab; SAE: serious AE. 
between the 2 treatment groups, with common reasons for discontinuing study agent including withdrawal of consent and AE.

The safety events through 1 year of the GO-ALIVE trial were consistent with other anti-TNF therapies in AS; although it should be noted that this study was not powered to detect rare events. Infections were the most common type of $\mathrm{AE}$, and the rates of infections were consistent with those in other populations managed with biologic agents ${ }^{16}$. Eight SAE occurred in GOL-treated patients; all but 2 (pneumonia and pulmonary tuberculosis) were considered by the investigators to be unrelated to study treatment. There were 3 serious infections among GOL-treated patients (pneumonia and pulmonary tuberculosis mentioned above, and appendicitis). The event of pulmonary tuberculosis was a new infection, not a reactivation, in a country where tuberculosis is more common than in Western Europe and North America. No opportunistic infections, demyelinating events, malignancies, or deaths occurred during the study. Infusion reactions were uncommon, and none were considered serious or severe or led to study discontinuation.

The totality of the results of the GO-ALIVE study demonstrated that treatment with IV GOL $2 \mathrm{mg} / \mathrm{kg}$ at weeks 0,4 , and every 8 weeks thereafter was effective in reducing the signs and symptoms of AS among adult patients with active disease despite treatment with NSAID, with sustained response through 1 year.

\section{ACKNOWLEDGMENT}

The authors thank Stephen Xu, MS, of Janssen Research \& Development LLC, for statistical support, and Rebecca Clemente, PhD, of Janssen Scientific Affairs LLC, for writing support.

\section{REFERENCES}

1. Kim Y, Oh HC, Park JW, Kim IS, Kim JY, Kim KC, et al. Diagnosis and treatment of inflammatory joint disease. Hip Pelvis 2017;29:211-22

2. Davis JC Jr., Revicki D, van der Heijde DM, Rentz AM, Wong RL, Kupper H, et al. Health-related quality of life outcomes in patients with active ankylosing spondylitis treated with adalimumab: results from a randomized controlled study. Arthritis Rheum 2007; 57:1050-7.

3. Ward MM, Deodhar A, Akl EA, Lui A, Ermann J, Gensler LS, et al American College of Rheumatology/Spondylitis Association of America/Spondyloarthritis Research and Treatment Network 2015 recommendations for the treatment of ankylosing spondylitis and nonradiographic axial spondyloarthritis. Arthritis Rheumatol 2016;68:282-98.
4. Umar N, Schaarschmidt M, Schmieder A, Peitsch WK, Schollgen I, Terris DD. Matching physicians' treatment recommendations to patients' treatment preferences is associated with improvement in treatment satisfaction. J Eur Acad Dermatol Venereol 2013; 27:763-70.

5. Scarpato S, Antivalle M, Favalli EG, Nacci F, Frigelli S, Bartoli F, et al; RIVIERA co-authors. Patient preferences in the choice of anti-TNF therapies in rheumatoid arthritis. Results from a questionnaire survey (RIVIERA study). Rheumatology 2010;49:289-94.

6. Deodhar A, Reveille JD, Harrison DD, Kim L, Lo KH, Leu JH, et al. Safety and efficacy of golimumab administered intravenously in adults with ankylosing spondylitis: results through week 28 of the GO-ALIVE study. J Rheumatol 2018;45:341-8.

7. Sieper J, Rudwaleit M, Baraliakos X, Brandt J, Braun J, Burgos-Vargas R, et al. The Assessment of SpondyloArthritis international Society (ASAS) handbook: a guide to assess spondyloarthritis. Ann Rheum Dis 2009;68 Suppl 2:ii1-44.

8. Machado P, Landewe R, Lie E, Kvien TK, Braun J, Baker D, et al; Assessment of SpondyloArthritis international Society. Ankylosing Spondylitis Disease Activity Score (ASDAS): defining cut-off values for disease activity states and improvement scores. Ann Rheum Dis 2011;70:47-53.

9. van der Heijde D, Lie E, Kvien TK, Sieper J, Van den Bosch F, Listing $\mathrm{J}$, et al; Assessment of SpondyloArthritis international Society (ASAS). ASDAS, a highly discriminatory ASAS-endorsed disease activity score in patients with ankylosing spondylitis. Ann Rheum Dis 2009;68:1811-8.

10. Garrett S, Jenkinson T, Kennedy LG, Whitelock H, Gaisford P, Calin A. A new approach to defining disease status in ankylosing spondylitis: the Bath Ankylosing Spondylitis Disease Activity Index. J Rheumatol 1994;21:2286-91.

11. Calin A, Garrett S, Whitelock H, Kennedy LG, O'Hea J, Mallorie P, et al. A new approach to defining functional ability in ankylosing spondylitis: the development of the Bath Ankylosing Spondylitis Functional Index. J Rheumatol 1994;21:2281-5.

12. Gorman JD, Sack KE, Davis JC Jr. Treatment of ankylosing spondylitis by inhibition of tumor necrosis factor alpha. N Engl J Med 2002;346:1349-56.

13. Ware JE Jr, Sherbourne CD. The MOS 36-item short-form health survey (SF-36). Conceptual framework and item selection. Med Care 1992;30:473-83.

14. Doward LC, Spoorenberg A, Cook SA, Whalley D, Helliwell PS, Kay LJ, et al. Development of the ASQoL: a quality of life instrument specific to ankylosing spondylitis. Ann Rheum Dis 2003;62:20-6.

15. Jenkinson TR, Mallorie PA, Whitelock HC, Kennedy LG, Garrett SL, Calin A. Defining spinal mobility in ankylosing spondylitis (AS). The Bath AS Metrology Index. J Rheumatol 1994;21:1694-8.

16. Dao KH, Herbert M, Habal N, Cush JJ. Nonserious infections: should there be cause for serious concerns? Rheum Dis Clin North Am 2012;38:707-25. 